\title{
Discrasia linfoide epiteliotrópica de células T. Tratamiento con radiación ultravioleta
}

\author{
Rosa María Lacy-Niebla, ${ }^{1}$ Sonia Toussaint-Caire ${ }^{2}$ y María Estela Mares-Navarro' \\ ${ }^{1}$ Unidad de Fototerapia; ${ }^{2}$ Servicio de Dermatopatología. Departamento de Dermatología. Hospital General Dr. Manuel Gea González, Ciudad de \\ México, México
}

\section{Resumen}

Introducción: Las discrasias linfoides epiteliotrópicas de células $T$ son un grupo de dermatosis inflamatorias poco frecuentes que pueden progresar a linfomas cutáneos. El tratamiento con radiación ultravioleta ha sido descrito como seguro y eficaz. Objetivo: Describir la respuesta al tratamiento, sus efectos secundarios y complicaciones. Método: Se administró radiación ultravioleta A con psoralenos (PUVA) a dos pacientes y radiación ultravioleta $B$ de banda estrecha (NB-UVB) a nueve pacientes, con diferentes discrasias. Resultados: Conformaron la serie siete mujeres y cuatro hombres, con edades de 5 a 30 años y con fototipos III y IV, con diagnóstico de discrasia linfoide epiteliotrópica hipopigmentada, pitiriasis liquenoide crónica, parapsoriasis hipopigmentada y púrpura pigmentada. Dos recibieron PUVA y nueve recibieron NB-UVB. Ocho alcanzaron respuesta completa y tres respuesta parcial con 10 a 119 sesiones de tratamiento. Ningún paciente presentó reactivación de la enfermedad después de 34 a 247 sesiones, y ninguno en tratamiento o seguimiento evolucionó a linfoma cutáneo. Los efectos secundarios fueron xerosis y prurito. Conclusión: El tratamiento de las discrasias linfoides con radiación ultravioleta es eficaz y seguro, con efectos secundarios leves y con respuestas exitosas en la mayoría de los pacientes, en tiempo y número de sesiones variables.

PALABRAS CLAVE: Discrasia linfoide de células T. Epiteliotrópica. Hipopigmentada. Fototerapia.

\section{Abstract}

Introduction: T-cell lymphoid dyscrasia is a group of different, infrequent, epitheliotropic inflammatory dermatosis that precede cutaneous $T$-cell lymphomas. Treatment with ultraviolet radiation is safe and efficacious. Objective: To describe responses to treatment, secondary effects and complications. Method: Eleven patients with different T-cell lymphoid dyscrasias were treated. Two received psoralens plus ultraviolet $A$ radiation (PUVA) and nine narrow band ultraviolet B radiation (NB-UVB). Results: Seven women and four men from 5 to 30 years-old and phototypes III and IV were included. They had hypopigmented epitheliotropic lymphoid dyscrasia, chronic pityriasis lichenoides, hypopigmented parapsoriasis and pigmented purpuric dermatoses. Two received PUVA and 9 NB-UVB. Eight achieved complete response and three partial response with 10 to 119 sessions. Any patient presented neither relapse nor progression to cutaneous T-cell lymphoma during treatment or in the follow up period after 34 to 247 sessions. Secondary effects were xerosis and mild pruritus. Conclusions: The majority of patients with T-cell lymphoid dyscrasias can be successfully and safely treated with minimal secondary effects after a variable number of sessions and periods of time with ultraviolet radiation.

KEY WORDS: T-cell lymphoid dyscrasia. Epitheliotropic. Hypopigmented. Phototherapy.

Correspondencia:

Rosa María Lacy-Niebla

E-mail: rosilacy@yahoo.com.mx
Fecha de recepción: 16-08-2018

Fecha de aceptación: 20-08-2018

DOI: 10.24875/GMM.18004577
Gaceta Med Mex. 2018;154(Suppl 2): S41-S49

Disponible en PubMed www.gacetamedicademexico.com 


\section{Introducción}

Antes de instalarse un linfoma cutáneo de células T (LCCT), de los que la micosis fungoide (MF) es el más frecuente, pueden pasar varios años teniendo los pacientes diferentes condiciones de la piel, antes consideradas solo inflamatorias, característicamente monoclonales u oligoclonales, con un perfil y un fenotipo relacionados con linfomas, como si se tratara efectivamente de ellos. A este grupo de dermatosis, que no cumplen con los criterios diagnósticos de la Sociedad Internacional para Linfomas Cutáneos, ${ }^{1}$ y que anteceden a los LCCT, se las ha denominado "discrasias linfoides cutáneas de células T». Esta clonalidad no es entonces característica únicamente de los linfomas, sino también de estos estados que los anteceden. ${ }^{2}$ Las dermatosis monoclonales se encuentran enlistadas en la Tabla 1.

Las discrasias linfoides cutáneas de células $T$ requieren tratamiento en tanto que son estados que anteceden a los LCCT, pero no existen protocolos de tratamiento específicos. Es por esta razón por lo que se aplican los tratamientos que se indican para las fases tempranas de los LCCT bien establecidos, entre ellos la exposición solar, emolientes, esteroides e inhibidores de la calcineurina tópicos, antihistamínicos sistémicos, así como fototerapia con radiación ultravioleta, tanto de tipo A con psoralenos (PUVA) como de tipo $B$ de banda estrecha (NB-UVB).

El objetivo de este trabajo es presentar nuestra experiencia en el tratamiento con radiación ultravioleta, PUVA y NB-UVB, en una serie de pacientes con discrasias linfoides cutáneas de células $T$, y difundir nuestros resultados para enriquecer la experiencia en el tratamiento de estas condiciones que pueden anteceder a los linfomas cutáneos y para las cuales no existen protocolos terapéuticos universales.

\section{Método}

Identificamos todos los pacientes de los archivos de nuestra Unidad de Fototerapia, con biopsia diagnóstica de discrasia linfoide epiteliotrópica, discrasia linfoide de interfaz, discrasia linfoide hipopigmentada, infiltrado linfoide atípico, paniculitis lobulillar linfocítica atípica, hiperplasia linfoide con eosinofilia, mucinosis folicular, linfocitosis foliculotrópica de células T, pitiriasis liquenoide crónica, parapsoriasis de grandes placas (PGP), parapsoriasis variedad hipopigmentada y eritrodermia clonal, registrados para tratamiento con radiación ultravioleta, desde el año de 2006 a la fecha.
Tabla 1. Discrasias linfoides cutáneas de células $T^{2}$

\begin{tabular}{l}
\hline Variantes de discrasias linfoides monoclonales \\
\hline 1. Variante de interfaz hipopigmentada \\
2. Dermatosis purpúricas pigmentadas \\
3. Paniculitis lobulillar linfocítica atípica \\
4. Hiperplasia siringolinfoide con eosinofilia \\
5. Mucinosis folicular idiopática/linfocitosis foliculotrópica de \\
células T \\
6. Pitiriasis liquenoide crónica \\
7. Parapsoriasis de grandes placas \\
8. Eritrodermia clonal
\end{tabular}

Todos los pacientes fueron diagnosticados con bases clínicas y los diagnósticos fueron confirmados con los estudios histológicos y de inmunohistoquímica por un dermatopatólogo experto. Los estudios de clonalidad no estuvieron disponibles. Las biopsias de piel, procesadas con las técnicas aceptadas y teñidas con hematoxilina y eosina, se sometieron a análisis con microscopio de luz; los estudios de inmunohistoquímica correspondientes se realizaron con el mismo tejido fijado en formalina y embebido en parafina, igualmente mediante técnicas y criterios aceptados. El panel de fenotipo incluyó los anticuerpos CD2, CD3, CD4, CD7 y CD8.

Se registraron los datos epidemiológicos de nombre, edad, sexo, fototipo de piel, topografía, morfología y duración de las lesiones. Los pacientes recibieron PUVA o NB-UVB. Se registraron el tiempo de tratamiento, el tiempo en el que presentaron mejoría clínica y los efectos secundarios o las complicaciones.

El protocolo de tratamiento con PUVA se inició con $1 \mathrm{~J} / \mathrm{cm}^{2}$ para pacientes con fototipo I a III o con $2 \mathrm{~J} / \mathrm{cm}^{2}$ para pacientes con fototipo IV a VI, con incrementos para todos de $1 \mathrm{~J} / \mathrm{cm}^{2}$ cada tres sesiones hasta la dosis máxima por sesión de 8 y $12 \mathrm{~J} / \mathrm{cm}^{2}$ para los pacientes con fototipo I a III y IV a VI, respectivamente, o hasta alcanzar la dosis terapéutica. Los tratamientos se administraron tres veces por semana en días alternos. Se realizaron pruebas de funcionamiento hepáti$\mathrm{co}$, para monitorizar el manejo de los psoralenos.

El protocolo de tratamiento con NB-UVB se aplicó ajustando la dosis inicial para cada paciente de acuerdo con el fototipo de piel $\left(400,500 \circ 600 \mathrm{~mJ} / \mathrm{cm}^{2}\right.$ para los pacientes con fototipos I y II, III y IV, y V y VI, respectivamente), con incrementos de 100 en $100 \mathrm{~mJ} / \mathrm{cm}^{2}$ por sesión de tratamiento, hasta alcanzar $180003000 \mathrm{~mJ} / \mathrm{cm}^{2}$ para los fototipos I a III y IV a VI, respectivamente, o la respuesta clínica. Los tratamientos se administraron tres veces por semana en días alternos. 
Tabla 2. Características clínicas y diagnósticos de los 11 pacientes con discrasia linfoide epiteliotrópica

\begin{tabular}{|c|c|c|c|c|c|c|c|}
\hline Paciente & Edad (años) & Sexo & Topografía & Morfología & Fototipo & $\begin{array}{c}\text { Tiempo de } \\
\text { evolución (años) }\end{array}$ & $\begin{array}{l}\text { Diagnóstico } \\
\text { clínico e } \\
\text { histológico }\end{array}$ \\
\hline 1 & 10 & M & Tronco, cuatro extremidades & Placas hipocrómicas escamosas & IV & 1.5 & DLEH \\
\hline 2 & 8 & M & $\begin{array}{l}\text { Cuatro extremidades, } \\
\text { mandíbula }\end{array}$ & Placas hipocrómicas escamosas & III & 4 & DLEH \\
\hline 3 & 20 & $\mathrm{H}$ & $\begin{array}{l}\text { Cuello, tronco, cuatro } \\
\text { extremidades }\end{array}$ & Máculas hipocrómicas & IV & 12 & DLEH \\
\hline 4 & 5 & M & $\begin{array}{l}\text { Generalizada, excepto } \\
\text { palmas y plantas }\end{array}$ & Placas hipocrómicas escamosas & IV & 2 & DLEH \\
\hline 5 & 30 & M & Tronco, cuatro extremidades & Máculas hipocrómicas & IV & 10 & DLEH \\
\hline 6 & 9 & $\mathrm{H}$ & $\begin{array}{l}\text { Tronco, cuatro } \\
\text { extremidades, cuello }\end{array}$ & $\begin{array}{l}\text { Máculas hipopigmentadas y } \\
\text { pápulas eritematoescamosas }\end{array}$ & IV & 3 & DLEH y PLC \\
\hline 7 & 54 & $\mathrm{H}$ & SD & SD & III & SD & $\begin{array}{l}\text { Púrpura } \\
\text { pigmentada }\end{array}$ \\
\hline 8 & 17 & M & Tronco, cuatro extremidades & Placas rosadas escamosas & III & 3 & Parapsoriasis \\
\hline 9 & 8 & $\mathrm{H}$ & $\begin{array}{l}\text { Tronco, extremidades } \\
\text { inferiores }\end{array}$ & $\begin{array}{l}\text { Placas y pápulas } \\
\text { eritematoescamosas }\end{array}$ & IV & 2 & $\begin{array}{l}\text { Parapsoriasis } \\
\text { y PLC }\end{array}$ \\
\hline 10 & 16 & M & $\begin{array}{l}\text { Generalizada, excepto } \\
\text { palmas y plantas }\end{array}$ & $\begin{array}{l}\text { Placas hipocrómicas y } \\
\text { escamosas }\end{array}$ & IV & 7 & PLC \\
\hline 11 & 18 & M & Tronco, cuatro extremidades & $\begin{array}{l}\text { Placas hipocrómicas escamosas } \\
\text { y máculas hipocrómicas }\end{array}$ & IV & 8 & DLEH \\
\hline
\end{tabular}

DLEH: discrasia linfoide epiteliotrópica hipopigmentada; H: hombre; M: mujer; PLC: pitiriasis liquenoide crónica; SD: sin datos.

Todos los pacientes, o sus padres o tutores, firmaron la carta de consentimiento informado y se sometieron a estudio oftalmológico previo a la aplicación del tratamiento y al finalizarlo. Durante las sesiones, los ojos se protegieron con goggles para fototerapia, los labios y los pezones con filtro solar de amplio espectro, y los genitales con tanga oscura. A los pacientes que recibieron PUVA se les enseñó el uso de lentes de policarbonato protectores durante todo el día del tratamiento. Todos los pacientes fueron instruidos en el uso del bloqueador solar y se les indicó aplicarse emolientes por lo menos dos veces al día y al salir de la cabina de tratamiento.

Se utilizó un dispositivo de fototerapia para cuerpo entero con sistema de control Smart Touch 3 Series 311/350 - 24/24 con 24 lámparas UVB/TL-01 de banda estrecha (311 nm pico) y 24 lámparas UVA (350 nm pico) de Daavlin.

La respuesta de los pacientes a la fototerapia se clasificó de acuerdo con la International Society for Cutaneous Lymphomas y la Cutaneous Lymphoma Task Force of the European Organisation for Research and Treatment of Cancer, ${ }^{3}$ que definen la respuesta completa como el aclaramiento del $100 \%$ de las lesiones clínicas; como enfermedad residual mínima cuando se presentan hallazgos histopatológicos en ausencia de lesiones clínicas; como respuesta parcial la desaparición del 50 al $99 \%$ de las lesiones; como enfermedad estable la desaparición de menos del $50 \%$ de las lesiones; y la progresión como cualquier recurrencia de la enfermedad en aquellos con respuesta completa.

\section{Resultados}

De 21 pacientes reunidos, cuatro se negaron a recibir tratamiento, seis lo abandonaron y perdieron seguimiento, y los 11 restantes reciben actualmente tratamiento o este se encuentra suspendido por mejoría clínica e histológica. Los pacientes fueron niños, adolescentes y adultos, y sus fototipos fueron medios (III-IV). Las características clínicas se resumen en la Tabla 2.

Este estudio incluyó 11 pacientes (4 hombres y 7 mujeres); la edad varió de 5 a 54 años y la duración de la enfermedad varió entre 1.5 y 12 años antes del diagnóstico.

Clínicamente todos los pacientes con la variedad de parapsoriasis y la variedad de discrasia linfoide hiopopigmentada presentaron manchas hipopigmentadas redondas a ovales con escama fina, aisladas y confluentes, distribuidas principalmente en el tronco, en áreas no fotoexpuestas y en las extremidades. No 
encontramos halo eritematoso, atrofia ni poiquilodermia (Figura $1 \mathrm{~A}$ y $\mathrm{B}$ ).

Los pacientes con pitiriasis liquenoide crónica presentaron pápulas eritematoescamosas diseminadas en el tronco y las cuatro extremidades (Figura $2 \mathrm{~A}$ y B).

Histológicamente, las discrasias linfoides epiteliotrópicas mostraron infiltrado linfocitario superficial con exocitosis hacia la epidermis (Figura 3). Las biopsias de los pacientes con parapsoriasis hipopigmentada mostraron resultados similares de hiperplasia epidérmica leve, hipopigmentación basal, número disminuido de melanocitos en la base de la epidermis, paraqueratosis focal, focos de espongiosis leve y exocitosis focal en la mayoría de los casos. La dermis mostró escaso infiltrado perivascular de linfocitos e histiocitos con extensión a la dermis papilar. Las variedades de interfaz presentaron vacuolización en la unión dermoepidérmica. No observamos células linfoides atípicas en ninguna de las biopsias examinadas.

Las tinciones de inmunohistoquímica mostraron inmunopositividad para CD3. Predominaron las células CD8+ sobre las CD4+. Ninguno de nuestros casos mostró menos del $10 \%$ de células T CD7+.

La inmunotinción con $\mathrm{S} 100$ realizada en dos casos mostró una disminución de la pigmentación basal y del número de melanocitos en relación a la piel no afectada.

Los pacientes tienen un tiempo promedio de tratamiento de 43.1 semanas, y dos pacientes requirieron 313.5 semanas. Las dosis terapéuticas de NB-UVB variaron de 1200 a $2200 \mathrm{~mJ} / \mathrm{cm}^{2}$ (promedio: $1722 \mathrm{~mJ} / \mathrm{cm}^{2}$ ), y las de PUVA de 3 a $7.5 \mathrm{~J} / \mathrm{cm}^{2}$ (promedio: $5.2 \mathrm{~J} / \mathrm{cm}^{2}$ ). Los pacientes consiguieron mejoría clínica en 10 a 119 sesiones, con un promedio de 39.3 sesiones con NB-UVB; y en 59 y 60 sesiones, con un promedio de 59.5 sesiones, con PUVA.

La mayoría de los pacientes no tuvieron efectos secundarios ni complicaciones del tratamiento. Los efectos secundarios fueron con mayor frecuencia xerosis y prurito leve. Una paciente presentó quemadura de primer grado en la cara por deficiencias en el uso del protector solar. La otitis y el granuloma anular de sendos pacientes fueron eventos independientes de la fototerapia. La reacción de fotosensibilidad se documentó en una paciente que se administró por su cuenta naproxeno y paracetamol (Tabla 3).

El tiempo de seguimiento se extendió de 4 a 545 semanas (de 1 mes a 10.4 años). En el $72.7 \%(n=8)$ se obtuvo respuesta completa y en el $27.2 \%(n=3)$ respuesta parcial. No hay pacientes con enfermedad estable ni quienes no hubieran presentado respuesta al tratamiento. El

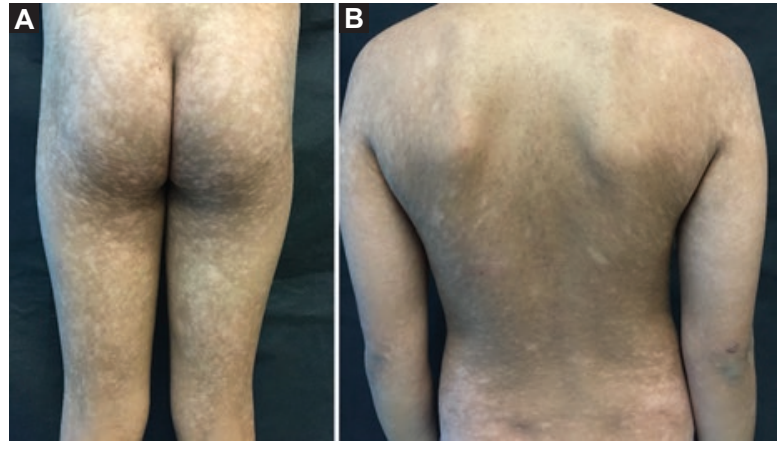

Figura 1 A y B. Apariencia clínica de la discrasia linfoide epiteliotrópica hipopigmentada.

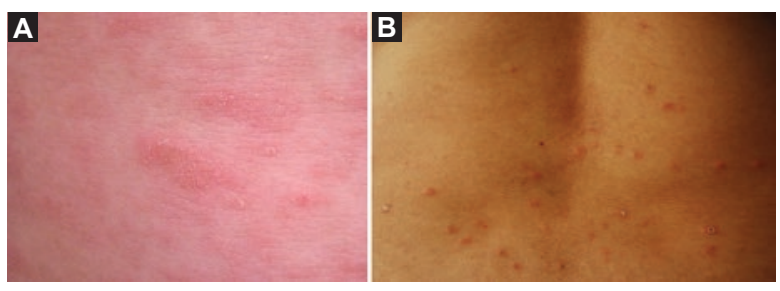

Figura 2 A y B. Pápulas eritematoescamosas de la pitiriasis liquenoide crónica.

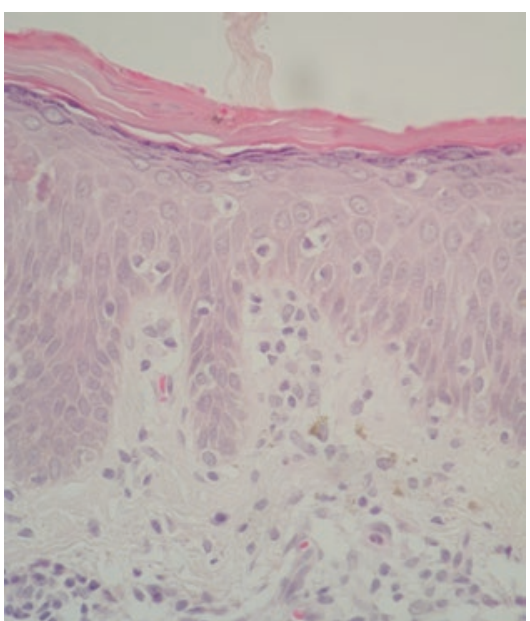

Figura 3. Discrasia linfoide epiteliotrópica que muestra linfocitos pequeños con epidermotropismo.

tiempo máximo de remisión completa ha sido de 10.4 años. La dosis total acumulada para los pacientes con respuesta completa es de 50160 a $129594 \mathrm{~mJ} / \mathrm{cm}^{2}$ para NB-UVB y de 79 a $247 \mathrm{~J} / \mathrm{cm}^{2}$ para PUVA.

Ningún paciente durante el tratamiento con fototerapia o en quienes se suspendió por respuesta completa han tenido reactivación de la enfermedad durante el seguimiento, ni progresión a MF. Los pacientes que tienen respuesta parcial tienen aún poco tiempo de fototerapia o acuden de manera muy irregular al tratamiento. El paciente 9 se perdió durante el seguimiento. 
Tabla 3. Tratamiento de nueve pacientes con fototerapia y de dos pacientes con fotoquimioterapia

\begin{tabular}{|c|c|c|c|c|c|c|}
\hline Paciente & $\begin{array}{c}\text { Tiempo de } \\
\text { tratamiento (semanas) }\end{array}$ & $\begin{array}{l}\text { Número de } \\
\text { sesiones }\end{array}$ & $\begin{array}{l}\text { Tipo de tratamiento } \\
\text { y dosis }\end{array}$ & $\begin{array}{l}\text { Sesiones para } \\
\text { la mejoría } \\
\text { clínica }\end{array}$ & $\begin{array}{l}\text { Estado } \\
\text { de la } \\
\text { enfermedad }\end{array}$ & $\begin{array}{l}\text { Efectos secundarios y } \\
\text { complicaciones }\end{array}$ \\
\hline 1 Zazilbe & 65 & 73 & NB-UVB $2100 \mathrm{~mJ} / \mathrm{cm}^{2}$ & 22 & $\mathrm{RC}$ & Ninguno \\
\hline 2 Jatniel & 52 & 80 & NB-UVB $1500 \mathrm{~mJ} / \mathrm{cm}^{2}$ & 14 & $\mathrm{RC}$ & Xerosis, prurito nocturno leve \\
\hline 3 Edgar & 38 & 45 & NB-UVB $1500 \mathrm{~mJ} / \mathrm{cm}^{2}$ & 44 & $\mathrm{RP}$ & $\begin{array}{l}\text { Xerosis. prurito leve, } \\
\text { Otitis }\end{array}$ \\
\hline 4 Mónica & 39 & 53 & NB-UVB 2000 mJ/cm² & 53 & $\mathrm{RC}$ & Ninguno \\
\hline 5 Saret & 62 & 80 & NB-UVB $1200 \mathrm{~mJ} / \mathrm{cm}^{2}$ & 54 & $\mathrm{RC}$ & Ninguno \\
\hline 6 Víctor & 52 & 85 & NB-UVB $1500 \mathrm{~mJ} / \mathrm{cm}^{2}$ & 14 & $\mathrm{RC}$ & Ninguno \\
\hline 7 Mario & 36 & 79 & PUVA $7.5 \mathrm{~mJ} / \mathrm{cm}^{2}$ & 59 & $\mathrm{RP}$ & Ninguno \\
\hline 8 Thania & 314 & 247 & PUVA $3 \mathrm{~mJ} / \mathrm{cm}^{2}$ & 60 & $\mathrm{RC}$ & Ninguno \\
\hline 9 Jesús & 313 & 156 & NB-UVB 2200 mJ/cm² & 119 & $\mathrm{RP}$ & Ninguno \\
\hline 10 Karina & 27 & 67 & NB-UVB $2000 \mathrm{~mJ} / \mathrm{cm}^{2}$ & 10 & $\mathrm{RC}$ & $\begin{array}{l}\text { Granuloma anular, reacción de } \\
\text { fotosensibilidad }\end{array}$ \\
\hline 11 Sandra & 17 & 34 & NB-UVB $1500 \mathrm{~mJ} / \mathrm{cm}^{2}$ & 24 & $\mathrm{RC}$ & $\begin{array}{l}\text { Quemadura en la cara, queilitis } \\
\text { contactada, xerosis, prurito }\end{array}$ \\
\hline
\end{tabular}

NB-UVB: radiación ultravioleta B de banda estrecha; PUVA: psoralenos con radiación ultravioleta A; RC: respuesta completa; RP: respuesta parcial.

\section{Discusión}

Todas las discrasias linfoides, que son poco frecuentes, tienen un curso benigno, aunque insidioso, crónico y recalcitrante. Las células $T$ poseen monoclonalidad u oligoclonalidad (determinada por Western blot o por reacción en cadena de la polimerasa), pero no las características citomorfológicas de malignidad, y potencialmente pueden evolucionar a LCCT, cuya incidencia es baja; no se conocen los eventos desencadenantes, y tampoco existe evidencia de hipersensibilidad o alergia, enfermedad del tejido conectivo ni otras condiciones linfoproliferativas. ${ }^{2}$

El diagnóstico de discrasia de células T se refuerza con la reducción en la expresión de los marcadores pan de células T CD7 (Leu 9) y CD62L (Leu 8) de los infiltrados. Algunas condiciones reactivas y reacciones linfomatoides, como las inducidas por algunos medicamentos, pueden manifestar reducciones sustanciales de la expresión de CD7. En cambio, CD62L ayuda a discriminar las discrasias linfoides de varias proliferaciones reactivas, como las reacciones de hipersensibilidad linfomatoides, por ejemplo, y de otros estados no neoplásicos, en los que no se ha documentado la disminución de su expresión. El marcador CD62L pertenece a la familia de las selectinas, que incluye las subcategorías L-selectina (designada como CD62L), E-selectina (CD62E) y P-selectina (CD62P), las cuales participan en las interacciones de las células inflamatorias y los endotelios. ${ }^{4}$

La indolente variante de interfaz hipopigmentada generalmente afecta a jóvenes de fototipos altos y se presenta de manera predominante en el tronco, en áreas fotoprotegidas por la ropa, con manchas solitarias o múltiples máculas hipopigmentadas con escama muy fina. Histológicamente se observa vacuolización de la capa basal por linfocitos epidermotrópicos con atipia cerebriforme de bajo grado, en general de fenotipo CD8+ CD4-, con reducción significativa de la expresión de CD7 y CD62L, del 70 y el $90 \%$, respectivamente, en los casos de Magro, et al.:; las proteínas citotóxicas intracitoplasmáticas de los linfocitos CD8+ condicionan la degeneración de queratinocitos basales y melanocitos. En la dermis papilar y superficial se encuentran melanófagos que contribuyen a la hipocromía. Los pacientes responden muy bien a la fototerapia, la quimioterapia tópica o los esteroides tópicos, y las lesiones se resuelven con repigmentación, aunque la hipocromía puede persistir. De 24 pacientes con esta condición que reportan Magro et al., ${ }^{5}$ la progresión a MF solo ocurrió en un paciente. En su estudio no se identificó clonalidad. ${ }^{5}$ Esta discrasia debe diferenciarse de la parapsoriasis en placas hipopigmentada, la 
hipopigmentación posinflamatoria, la hipomelanosis macular progresiva, el vitíligo, la lepra, la tiña versicolor, la sarcoidosis, la pitiriasis alba y, de manera muy importante, de la poco frecuente MF variedad hipopigmentada, que ocurre en pacientes más jóvenes que otros con distintas formas clínicas de MF, y con piel oscura, tal como sucede con los pacientes con esta variedad de discrasia. ${ }^{6,7}$

Las dermatosis purpúricas liquenoides son un grupo de enfermedades idiopáticas que preferentemente afectan las extremidades inferiores y se caracterizan por petequias y coloración ocre. El grupo incluye la púrpura de Schamberg (lesiones en «pimienta de cayena» en las piernas), la de Majocchi (glúteos, muslos y tronco, con placas eritematosas anulares), la de Gougerot-Blum (pápulas que semejan liquen plano y púrpura), el liquen aureus (placas solitarias induradas doradas con escama fina en los maléolos mediales) y la eccematoide de Doucas y Kapetanakis (piernas con púrpura y eccema). En ellas se observa un infiltrado en banda, con esclerosis y depósitos de hemosiderina. Usualmente disminuye la expresión de CD7 y de CDL62, como en la MF. Las mismas clonas de linfocitos $T$ se encuentran en múltiples biopsias a lo largo del tiempo, sin identificarse un detonador antigénico. ${ }^{2,8}$

Los pacientes con paniculitis lobulillar linfocítica atípica presentan placas evanescentes que lucen como equimosis, principalmente en la parte proximal de las extremidades; parecen relacionarse con el linfoma de células T subcutáneo tipo paniculitis. El infiltrado lo componen linfocitos levemente atípicos, sin necrosis ni hemofagocitosis como en el linfoma de células $T$ subcutáneo tipo paniculitis, y puede observarse mucina. Se pierde la expresión de CD5, de la selectina CD62L y de CD7. Puede disminuir un poco la relación de linfocitos CD4:CD8 y se expresa $\beta-\mathrm{F} 1$ (marcador del heterodímero $\alpha \beta$ del receptor de células $\mathrm{T}$ ), que confirma el diagnóstico. ${ }^{2}$

La hiperplasia siringolinfoide con eosinofilia se presenta con placas alopécicas eritematosas 0 hipopigmentadas, casi siempre con anhidrosis. El infiltrado linfoide se sitúa alrededor de las glándulas sudoríparas ecrinas con hiperplasia variable del epitelio ecrino, y también es foliculotrópico con o sin depósitos de mucina; los linfocitos son de pequeños a medianos, con leve atipia. El exantema laterotorácico unilateral es una variante que se observa en la infancia. ${ }^{2}$

La mucinosis folicular idiopática es primaria o inflamatoria, pero puede tener cambios histológicos de MF mucinosa en la que se observa mucina principalmente en el infundíbulo dentro del folículo piloso, con clonalidad persistente de los linfocitos que infiltran la vaina radicular externa y que se acompañan de eosinófilos; en lugar de mucina puede haber hiperqueratosis y retención de queratina en los folículos, que clínicamente evidencian comedones. Puede ser una sola placa eritematosa túmida o varias pápulas confluentes que predominan en la cara y la piel cabelluda de infantes y adultos jóvenes, no siempre con alopecia, y puede tener resolución espontánea en muchos pacientes, aunque no es posible predecir la evolución. ${ }^{2}$

La variedad crónica de la pitiriasis liquenoide (PLC) tiende a persistir con remisiones y exacerbaciones de brotes de pápulas de color café eritematosas y con escama adherente. Se produce una dermatitis de interfaz con exocitosis de linfocitos pequeños, hiperqueratosis, disqueratosis y extravasación focal de eritrocitos superficial y en la dermis media. No es raro encontrar atipia en el componente linfocitario intraepidérmico, incluyendo la apariencia cerebriforme. Los linfocitos son predominantemente CD4+ y puede detectarse reducción de la expresión de CD7 o CD62L, o de ambos. En un estudio de Magro, et al. se encontró monoclonalidad en el $52 \%$ de las PLC de su serie. Prácticamente no hay eosinófilos en el infiltrado. La progresión a MF sucede en algunos casos. ${ }^{2}$

Las PGP engloban un grupo de lesiones que simulan parches o placas tempranos de MF. Las placas se asientan en los glúteos, el tronco, los muslos, la cara interna de los brazos y la región submamaria. Pueden presentar atrofia y poiquilodermia. Se observa paraqueratosis en un estrato córneo hiperqueratósico e infiltrado perivascular e intersticial de linfocitos pequeños sin atipia cerebriforme significativa; el epidermotropismo afecta a todas las capas de la epidermis, principalmente las más superficiales, donde pueden formarse pseudomicroagregados de Pautrier de linfocitos pequeños e histiocitos; también hay fibroplasia de la dermis papilar. No se observan eosinofilia tisular ni edema, agregados de Pautrier ni colonización basal. Los linfocitos son CD4+ y hay cierta disminución de la expresión, pero no pérdida, de CD7 o CD5 y CD62L; también hay linfocitos CD8+ y CD56+ en cantidad variable. Los linfocitos CD4+ y CD8+ que presentan restricción clonal pueden presentar deleción de CD7 y CD62L. En el estudio de Väkevä, et al., ${ }^{9}$ el $35 \%$ de los pacientes con PGP desarrollaron MF confirmada histológicamente en una media de 6 años. La variedad de parapsoriasis en placas hipopigmentada, poco común, debe diferenciarse de otras leucodermias, en especial de la MF hipopigmentada, ${ }^{10}$ dado que las condiciones demográficas y el fototipo de piel 
en ambas son muy similares. Se ha considerado una variante de la arapsoriasis de pequeñas placas (PPP). ${ }^{11}$

Finalmente, la eritrodermia clonal, crónica y recalcitrante, se parece mucho a la eritrodermia del síndrome de Sézary, excepto en que carece de una cuenta de células de Sézary mayor de 1000 por $\mathrm{mm}^{2}$ en sangre periférica y de una relación de CD4:CD8 mayor de 10:1. Los pacientes tienen prurito importante, queratodermia palmoplantar, ectropión, distrofia ungueal y alopecia. El 5 a $10 \%$ de los casos evolucionan a síndrome de Sézary. ${ }^{2}$

En nuestra serie predominaron los casos de discrasia linfoide epiteliotrópica hipopigmentada y de parapsoriasis variedad hipopigmentada; la PLC se presentó sola o con discrasia linfoide epiteliotrópica hipopigmentada, y junto con un caso de parapsoriasis, y tuvimos un solo paciente con púrpura pigmentada. Hemos observado que las discrasias pueden presentarse como una sola variedad o combinarse entre ellas en el mismo paciente. Desconocemos si la asociación entre ellas contribuye al riesgo de progresión a linfomas de células T como la MF.

Todos estos estados precancerosos del LCCT, que son de curso benigno y no siempre preceden al LCCT, se presentan característicamente con inflamación crónica, que condiciona proliferación linfocítica y que hace que poco a poco se adquieran condiciones de proliferación y antiapoptosis, al sufrir expansión clonal. Estos linfocitos proliferan como respuesta a los estímulos de las células presentadoras de antígenos; las citocinas de esta respuesta de las células $T$ reguladoras, a través de la interleucina 10 y del factor transformante beta, explican que el LCCT evolucione de una reacción inflamatoria originada por algún antígeno. Las células clonales probablemente surjan de las células inflamatorias que no pueden responder a mecanismos inmunitarios autorreguladores. Esta expansión clonal conduce a la progresión tumoral con la emergencia de más subclonas agresivas. ${ }^{2}$

Los eventos que hacen que una población de células inflamatorias evolucione a una población celular neoplásica incluyen criterios clínicos, como la progresión a placas y tumores; histológicos y citomorfológicos, como las células atípicas en el contexto de patrones histológicos diferentes; fenotípicos, como la pérdida de los marcadores de diferenciación o la ganancia de los de proliferación; y genotípicos, como la proliferación clonal. Estos procesos de condicionamiento tumoral hacia MF surgen de varios factores individuales y exógenos (antígenos ambientales 0 superantígenos bacterianos), o de factores endógenos (como las vías de citocinas autocrinas y la interacción de B7/CD28). ${ }^{12}$

La combinación de las características clínicas de esta variante hipopigmentada de las discrasias linfoides, de los datos histopatológicos y de la inmunohistoquímica tiene una sensibilidad de más del $80 \%$ en varios estudios para precisar los diagnósticos. ${ }^{6}$ Además, el rearreglo genético que defina la monoclonalidad, la oligoclonalidad o la policlonalidad de estas condiciones resulta de gran ayuda para poder clasificar los casos. ${ }^{13}$

Es nuestra preocupación que muchos casos de MF variedad hipopigmentada puedan ser confundidos con discrasias linfoides, principalmente con la variedad hipopigmentada, que son de curso benigno y que puedan ser diagnosticadas como MF, y por lo tanto ser sobretratadas con terapias agresivas que no son necesarias; o bien, en el caso contrario, que dejemos pasar el diagnóstico de las MF hipopigmentadas bien establecidas, considerándolas benignas, y que entonces progresen a fases más avanzadas y causen mayor morbilidad a los pacientes. No documentamos progresión a MF durante el tratamiento ni en el seguimiento en ninguno de nuestros casos.

\section{Tratamiento}

La radiación ultravioleta es un tratamiento aceptado universalmente para la psoriasis, otras enfermedades inflamatorias de la piel y algunos linfomas cutáneos en sus fases tempranas o en sus fases precursoras (como las discrasias linfoides). Sus efectos se deben a los cambios que ocasionan al ADN de las células de la piel, en sus proteínas y sus lípidos, en la señalización celular y en la expresión genética a través de la liberación de citocinas y de factores de crecimiento. De este modo, los linfocitos radiados sufren apoptosis cuando se rebasan los mecanismos de detención del ciclo celular y reparación molecular que causa la radiación. Ejerce efectos de inmunomodulación y antiproliferación. En este principio se basan las respuestas terapéuticas de las discrasias linfoides epiteliotrópicas y de los linfomas de células T cutáneos en fases tempranas.

Las discrasias linfoides han sido tratadas con éxito con fototerapia en sus diferentes modalidades, con el objeto de evitar su progresión a LCCT. No existen protocolos específicos para estas condiciones cutáneas, pero se han descrito los mismos para el LCCT y la parapsoriasis en placas. Los tratamientos para infantes y adolescentes con MF se basan en las estrategias usadas en los pacientes adultos y de acuerdo con su 
estadificación. ${ }^{14}$ La fotoquimioterapia y la fototerapia se indican para las fases tempranas de los LCCT, es decir, para los estadios IA, IB y IIA de la MF; ambas modalidades adquieren carácter paliativo en estadios más avanzados. ${ }^{15-17}$

Las respuestas completas con NB-UVB en el LCCT en fases tempranas tienen un rango del 54 al $90 \%$. Para los pacientes con MF sin terapia de mantenimiento, el índice de recaídas va del 29 al $100 \%$, con un tiempo libre de enfermedad de 5.9 a 14.5 meses. Para quienes han tenido mantenimiento, los índices de recidiva son del 4 al $83 \%$, con un tiempo libre de lesiones de 3 a 26 meses, por lo que hay cierto beneficio con la terapia de mantenimiento. ${ }^{3}$ Todos nuestros pacientes, tanto los tratados con PUVA como los que recibieron NB-UVB, no han presentado recaídas al momento de esta publicación; algunos apenas con 4 semanas de suspensión de tratamiento y otros con un poco más de 10 años de seguimiento sin tratamiento.

En un estudio retrospectivo de Väkevä, et al. ${ }^{8}$ se trataron pacientes con PGP, PPP y MF con fototerapia. Al final del estudio, no hubo diferencia significativa entre los grupos tratados con radiación ultravioleta y los no tratados en relación con el desarrollo de MF, tanto en PPP como en PGP, ni en la tendencia a la remisión en los pacientes tratados con o sin fototerapia; por otro lado, sus resultados arrojan el hecho de que la fototerapia no es dañina para los pacientes con parapsoriasis, y que la mayoría de los pacientes con PPP, como los de PGP, curan. La remisión más larga que conseguimos en nuestro grupo de pacientes es de 10 años; esta paciente tenía diagnóstico de parapsoriasis y recibió PUVA de tratamiento. No existe un consenso uniforme sobre cuál es el tiempo de remisión para considerar la curación de la enfermedad.

La NB-UVB tiene un muy buen perfil de seguridad, pero debido a la falta de evidencia, tanto la PUVA como la NB-UVB no han sido aprobadas para su uso en pacientes infantes con diferentes condiciones de piel, como la psoriasis. Sin embargo, las guías de tratamiento de la psoriasis indican que la fototerapia con NB-UVB puede ser una terapia segura en pacientes infantes seleccionados. ${ }^{18}$ En la serie que presentamos aplicamos a 9 de los 11 pacientes esta modalidad de tratamiento, sin más efectos secundarios que sequedad de la piel y prurito. Ocho pacientes eran menores de 18 años (Figura 4 A y B).

Aunque Lambroza, et al. $^{16}$ reportaron en 1995 remisiones completas y rápidas en seis de siete pacientes con MF hipopigmentada tratados con PUVA, ${ }^{16}$ y la modalidad de baño-PUVA es una buena opción

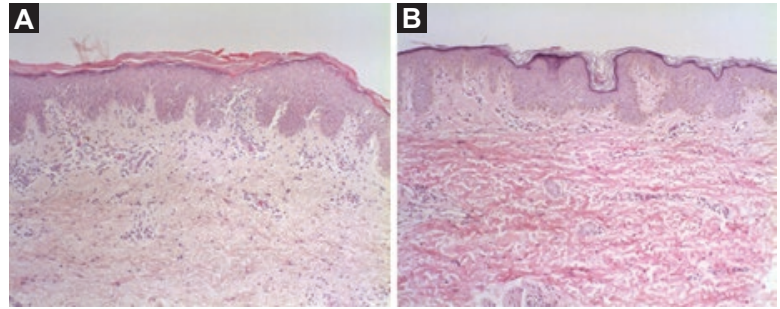

Figura 4. Mejoría histológica evidente de la discrasia linfoide epiteliotrópica después de 5 meses de tratamiento con NB-UVB. A: antes del tratamiento. B: después del tratamiento.

para tratar las MF foliculotrópicas, especialmente del tipo superficial, y las fases tempranas de MF refractarias al tratamiento con NB-UVB sin los efectos sistémicos secundarios de los psoralenos orales, principalmente los oculares, ${ }^{17}$ la elección actualmente es NB-UVB. Ventajosamente, la NB-UVB no requiere el uso de fotosensibilizadores como los psoralenos para la PUVA, y parece que tiene menor potencial carcinógeno. También tiene mayores efectos inmunosupresores que la NB-UVB, en comparación con la PUVA. ${ }^{19}$ Hofer, et al. ${ }^{20}$ reportaron, en 1999, una serie de seis casos de MF en estadios tempranos y 14 con PPP, en la que por los excelentes resultados obtenidos con la terapia con NBUVB se consideró a esta como el tratamiento de primera elección. Los pacientes fueron tratados tres 0 cuatro veces por semana, por 5-10 semanas, y se obtuvo remisión en 19 de ellos después de un promedio de 20 sesiones, con recaídas en todos los pacientes después de un tiempo promedio de 6 meses. Así mismo, Clark, et al. ${ }^{21}$ reportaron en el año 2000 resultados similares y recomendaciones al tratar a ocho pacientes con MF en fases tempranas con NB-UVB. Sus pacientes recibieron el tratamiento tres veces por semana, con remisión clínica completa después de 9 semanas, con un promedio de 26 sesiones, y una duración de la remisión de 20 meses en promedio. Gathers et al., ${ }^{22}$ de 24 pacientes con MF en fases tempranas tratados con NB-UVB, alcanzaron remisión completa en 13 (54.2\%), en 7 (29.2 \%) respuesta parcial y en $4(16.7 \%)$ no obtuvieron respuesta. Cuatro de los pacientes con respuesta completa tuvieron recaída en un promedio de 12.5 semanas. Boulos, et al. ${ }^{14}$ hicieron una descripción de 34 pacientes con MF de inicio en menores de 20 años, en la que en 21 de ellos tuvieron un índice de respuesta a la NB-UVB del $81 \%$.

El tratamiento con NB-UVB puede combinarse con esteroides tópicos y sigue siendo una opción segura, ya que los agentes alquilantes no se recomiendan debido a la carcinogenicidad asociada y los potenciales riesgos a largo plazo. ${ }^{14}$ 
Dos pacientes de la presente serie fueron tratados con PUVA, ya que anteriormente los psoralenos se encontraban disponibles; más tarde, debido a la carencia de estos y a las razones antes expuestas, los otros pacientes se trataron con NB-UVB, con muy buen perfil de seguridad y sin efectos secundarios ni complicaciones, excepto piel seca y prurito ocasionales; el único caso de quemadura se debió a deficiencias en el uso del protector solar. Todos los pacientes recibieron emolientes y algunos otros esteroides de mediana a alta potencia.

\section{Conclusión}

En la evaluación de los pacientes con lesiones hipopigmentadas idiopáticas debemos considerar que requieren biopsia y seguimiento para evaluar su clasificación en los estados discrásicos monoclonales u oligoclonales con posibilidad de evolución a MF, y también para evaluar la respuesta al tratamiento.

En este estudio presentamos 11 pacientes con discrasia linfoide de células T epiteliotrópica, seis de ellos con la variedad hipopigmentada, uno con PLC, uno con discrasia linfoide epiteliotrópica hipopigmentada y PLC, uno con púrpura pigmentada, uno con parapsoriasis hipopigmentada y uno más con parapsoriasis hipopigmentada y PLC, que fueron exitosamente tratados con seguridad con radiación ultravioleta, siendo todos ellos jóvenes, siete menores de 18 años (edades a las que predominantemente afectan las discrasias linfoides epiteliotrópicas (DEL)), y los otros dos pacientes tenían 30 y 54 años. El índice de progresión y conversión a MF que observamos en nuestro trabajo fue nulo, por lo que no se equipara al de la conversión reportada de PPP a MF, del $10 \%^{8}$ vs el $35 \%$ en PGP. ${ }^{11}$

El objetivo del tratamiento de estos pacientes con fototerapia fue llevarlos a un estado de remisión completa. Es también objetivo del tratamiento el conseguir que los periodos de remisión sean lo más largos posible para que las recaídas se presenten lejanamente, y que si estas se van a presentar, sean de la misma o menor intensidad. Si tal fuera el caso, los pacientes deben recibir de nuevo ciclos de fototerapia para volver a un estado de remisión y minimizar ese riesgo de progresión a LCCT. Al momento del corte para realizar este trabajo, ninguno de nuestros pacientes mostró recaída ni ha requerido, por lo tanto, otros ciclos de tratamiento. La remisión más larga conseguida es de 10 años. Las respuestas parciales que obtuvimos se debieron al tiempo corto de tratamiento de dos pacientes, en quienes esperamos respuesta completa con mayor número de sesiones, y a la inconstancia e irregularidad en la asistencia al tratamiento en otro paciente.

La fototerapia es útil y segura como tratamiento para las discrasias linfoides epiteliotrópicas.

\section{Bibliografía}

1. Pimpinelli N, Olsen EA, Santucci M, Vonderheid E, Haeffner AC, Stevens $\mathrm{S}$, et al. International Society for Cutaneous Lymphoma. Defining early mycosis fungoides. J Am Acad Dermatol. 2005;53:1053-65.

2. Guitart J, Magro C. Cutaneous T-cell lymphoid dyscrasia. A unifying term for idiopathic chronic dermatoses with persistent T-cell clones. Arch Dermatol. 2007;143:921-32.

3. Olsen EA, Hodak E, Anderson Th, Carter JB, Henderson M, Cooper K, et al. Guidelines for phototherapy of mycosis fungoides and Sézary syndrome syndrome: a consensus statement of the United States Cutaneous Lymphoma Consortium. J Am Acad Dermatol. 2016;74:27-48.

4. Magro CM, Sachdeva MP, Crowson AN, Barusevicius A, Baran PN Kovatich AJ. The application of a monoclonal antibody to CD62L on paraffin-embedded tissue samples in the assessment of the cutaneous T-cell infiltrates. J Cutan Pathol. 2005;32:12-20.

5. Magro CM, Hagen JW, Crowson AN, Liu YC, Mihm M, Drucker NM, et al. Hypopigmented interface T-cell discrasia: a form of cutaneous T-cell discrasia distinct from hypopigmented mycosis fungoides. J Dermatol. 2014:41:609-17.

6. Abdel-Halim M, El-Nabarawy E, El Nemr R, Hassan AM. Frequency of hypopigmented mycosis fungoides in Egyptian patients presenting with hypopigmented lesions of the trunk. Am J Dermatopathol. 2015;0:1-7.

7. Akaraphanth R, Douglass MC, Lim HW. Hypopigmented mycosis fungoides: treatment and a 6 1/2-year follow-up of 9 patients. J Am Acad Dermatol. 2000;42:33-9.

8. Magro CM, Schaefer JT, Crowson AN, Li J, Morrison C. Pigmented purpuric dermatosis: classification by phenotypic and molecular profiles. Am J Clin Pathol. 2007;128:218-29.

9. Väkevä L, Sarna S, Vaalasti A, Pukkala E, Kariniemi A-L, Ranki A. A retrospective study of the probability of the evolution of parapsoriasis en plaques into mycosis fungoides. Arch Derm Venereol. 2005;85:318-23.

10. Castano E, Glick S, Wolgast L, Naeem R, Sunkara J, Elston D, et al. Hypopigmented mycosis fungoides in childhood and adolescence: a long-term retrospective study. J Cutan Pathol. 2013;40:924-34.

11. El-Darouti MA, Fawzy MM, Hegazy RA, Abdel Hay RM. Hypopigmented parapsoriasis en plaque, a new, overlooked member of the parapsoriasis family: a report of 34 patients and a 7-year experience. J Am Acad Dermatol. 2012;67:1182-8.

12. Burg G, Dummer R, Haeffner A, Kempk W, Kadin M. From inflammation to neoplasia. Mycosis fungoides evolves from reactive inflammatory conditions (lymphoid infiltrates) transforming into neoplastic plaques and tumors. Arch Dermatol. 2001;137:949-52.

13. Klemke C-D, Dippel E, Dembinski A, Pönitz N, Assaf C, Hummel M, et al. Clonal $\mathrm{T}$ cell receptor $\mathrm{\gamma}$-chain gene rearrengement by PCR-based $\mathrm{Ge}$ neScan analysis in the skin and blood of patients with parapsoriasis and early-stage micosis fungoides. J Pathol. 2002;197:348-54.

14. Boulos S, Vaid R, Aladily TN, Ivan DS, Talpur R, Duvic M. Clinical presentation, immunopathology, and treatment of juvenile-onset mycosis fungoides: a case series of 34 patients. J Am Acad Dermatol. 2014;71:1117-26.

15. Carrascosa JM, Gardeazábal J, Pérez-Ferriols A, Alomar A, Manrique $P$, Jones-Caballero $M$, et al. Documento de consenso sobre fototerapia: terapias PUVA y UVB de banda estrecha. Actas Dermosifiliogr. 2005;96:635-58.

16. Lambroza E, Cohen SR, Phelps R, Lebwohl M, Braverman IM, DiCostanzo D. Hypopigmented variant of mycosis fungoides: demography, histopathology, and treatment of seven cases. J Am Acad Dermatol. 1995;32:987-93.

17. Pavlotsky F, Hodak E, Amitay DB, Barzilai A. Role of bath psoralen plus ultraviolet $A$ in early-stage mycosis fungoides. J Am Acad Dermatol. 2014;71:536-41.

18. Lacy-Niebla RM, Poletti-Vázquez ED, Aguilar-Donis A. Infantes con psoriasis: ¿fototerapia? Dermatologia CMQ. 2016;14:228-31.

19. Young AR. Carcinogenicity of UVB phototherapy assessed. Lancet. 1995;345:1431-2

20. Hofer A, Cerroni L, Kerl H, Wolf P. Narrowband (311-nm) UVB therapy for small plaque parapsoriasis and early-stage mycosis fungoides. Arch Dermatol. 1999;135:1377-80.

21. Clark C, Dawe R, Evans A, Lowe G, Ferguson J. Narrowband TL-01 phototherapy for patch-stage mycosis fungoides. Arch Dermatol. 2000;136:748-52.

22. Gathers RC, Scherschun L, Malick F, Fivenson DP, Lim HW. Narrowband UVB phototherapy for early-stage mycosis fungoides. J Am Acad Dermatol. 2002;47:191-7. 